\title{
Model of thermal comfort in the hyperbaric facility
}

\author{
Anna Majchrzycka, Ph. D. \\ West Pomeranian University of Technology, Szczecin
}

\begin{abstract}
The paper discusses the mathematical model of thermal comfort in the hyperbaric facility. Based on human thermal balance and thermal comfort conditions the comfort equation for the hyperbaric environment was derived. The comfort equation enables to calculate all those combinations of the diver's activity, clothing (thermal insulation, moisture permeation factor) and environmental variables (temperature, pressure, composition, relative humidity and velocity of the breathing gas and mean radiant temperature), which would create thermal comfort in the hyperbaric environment. The paper presents also the solution of thermal comfort equation for dives up to the depth of $g=590 \mathrm{~m}$, with helium-oxygen and hydrogen-oxygen breathing mixture, as well as the comfort diagrams.
\end{abstract}

Keywords: comfort temperature; human balance; hyperbaric environment

\section{INTRODUCTION}

Saturation diving is the diving operation that enables man to live and work in the sea-going deep dive systems or to be trained in the land-based hyperbaric complexes for a long time. Advanced diving technique requires an optimal breathing gas to be selected. The use of air as the breathing gas is limited because of oxygen toxicity and narcotic effect of nitrogen $[5,14,15]$. Breathing mixtures used in deep diving consist of oxygen that meets demands for metabolic needs and inert gases (helium, nitrogen, hydrogen). Moreover, breathing gas contains contaminants generated by the divers during exposure and some gaseous additives improving voice communication (sulphur hexafluoride, carbon tetrafluoride) or freon used as fire extinguishing agent [5].

Saturation diving is based on the principle that the tissues and blood of a diver's body absorb inert gases and reach saturation point where the pressure of the dissolved gas in the blood and tissues is the same as that of the gas in the lungs. The diving technique is based on the fact that once the saturation point has been reached the diver can safely remain saturated for a long period, and the diver's obligation for decompression does not increase with further exposure. It makes deep diving operations more efficient.

Most of the deep diving experience is based on the breathing gas containing helium, however the last years have shown that hydrogen also can be used [4] as the component of breathing mixtures used in saturation diving There were also some trials with experimental breathing mixtures containing the other inert gases: neon, argon [5].

Helium and hydrogen causes certain thermal problems related to dangerous cooling of the divers. This is due to the high thermal conductivity and specific heat of helium and hydrogen. Therefore, comfort temperature in the hyperbaric environment increases with the total pressure of gas and should be maintained at a level higher than that in atmospheric air $[8,9,11,14,15,16,17,18,19,20]$.

A see-going deep dive system presented in Fig.1 consists of the support vessel, deck decompression chamber and diving bell. A land-based hyperbaric facility presented in Fig. 2 includes one or a series of the hyperbaric chambers where the divers live and work at the pressure which simulates the ambient one at their work site. Dry or wet chambers of the land-based hyperbaric facility are connected by locks. The chambers can be maintained at the same pressure or different one depending on the goals of hyperbaric tests (medical tests, equipment tests, etc).

One of the major tasks of the life support systems of the hyperbaric facilities is to create the environment which maintains the safe level of oxygen partial pressure, required level of contaminants and the thermal comfort for the divers [15]. The thermal comfort is defined by ASHRAE standard 55-66 [2], as a state of mind that express satisfaction with the surrounding environment.

There are many variables which influence the thermal comfort condition in hyperbaric environment: pressure, 


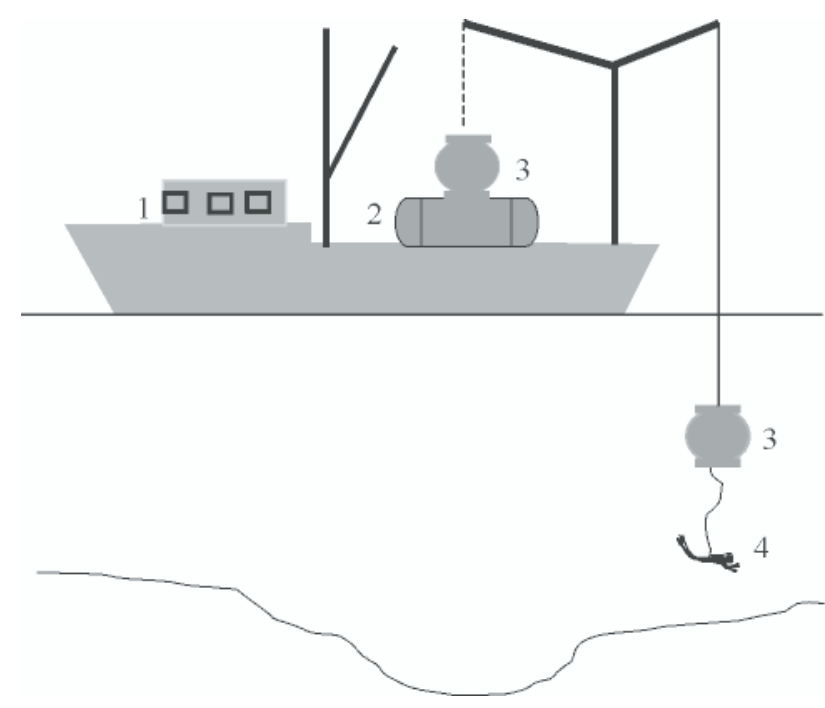

Fig. 1. Sea-going deep dive hyperbaric system: 1) support vessel, 2) deck decompression chamber, 3) diving bell, 4) diver

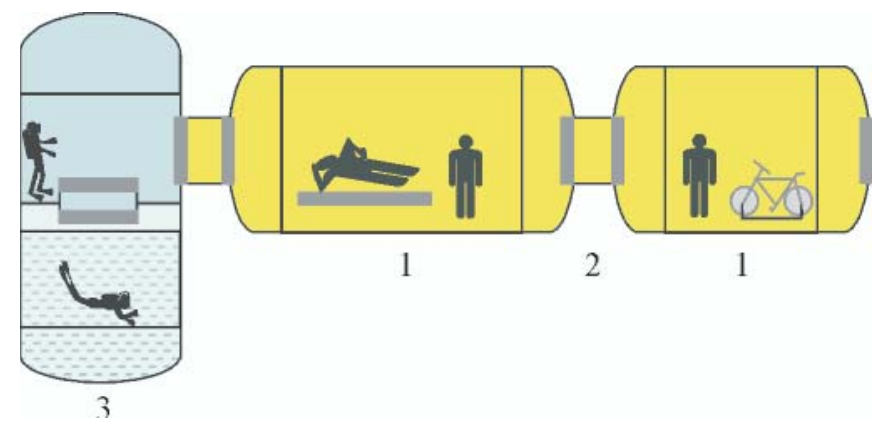

Fig. 2. Land-based hyperbaric complex: 1) dry hyperbaric chamber, 2) lock, 3) ,,wet-pot" hyperbaric chamber

composition, temperature, humidity and relative velocity of the breathing mixture, mean radiant temperature, activity level and thermal insulation of the diver's clothing. It is impossible to consider the effect of any of the above mentioned variables independently. Thermal comfort can be reached by many different combinations of the environmental variables, however there are also some irrational (human) factors (stress, fatigue, etc.) which should be taken into consideration. Fig. 3 presents the factors (grouped in six blocks - pieces of thermal comfort puzzle supplemented with block of irrational factors.) which affect thermal comfort in the hyperbaric facility.

Not many earlier comfort studies for the hyperbaric environment have taken all the above mentioned variables into account. However, few studies have been performed on men to ascertain the comfort conditions experimentally and theoretically $[3,8,9,11,13,16,18,19,20]$.

In order to determine the comfort temperature in the hyperbaric environment the comfort equation based on the mathematical model of human body thermal exchange, was developed. Mathematical modelling of thermal comfort enables to assure the comfort temperature by taking into account the most important variables which affect thermal comfort in the hyperbaric facility:

$$
\mathrm{t}=\mathrm{f}\left(\mathrm{p}, \mathrm{x}_{\mathrm{i}}, \mathrm{c}_{\mathrm{p}}, \lambda, \eta, \rho, \dot{\mathrm{q}}_{\mathrm{m}}, \mathrm{I}_{\mathrm{cla}}, \mathrm{t}_{\mathrm{r}}, \varphi, \mathrm{v}\right)
$$

\section{THERMAL COMFORT EQUATION FOR THE HYPERBARIC FACILITY}

The overall steady- state thermal balance of the human body can be expressed [2] with the following equation:

$$
\dot{\mathrm{Q}}_{\mathrm{m}}-\dot{\mathrm{Q}}_{\mathrm{e}}-\dot{\mathrm{Q}}_{\mathrm{o}}=\dot{\mathrm{Q}}_{\mathrm{p}}=\dot{\mathrm{Q}}_{\mathrm{c}}+\dot{\mathrm{Q}}_{\mathrm{r}}
$$

The equation (2) expresses that the flux of metabolic heat production, $\dot{\mathrm{Q}}_{\mathrm{m}}$, minus the flux of heat loss by evaporation from the skin, $\dot{Q}_{\mathrm{e}}$, and that by respiration, $\dot{\mathrm{Q}}_{\mathrm{o}}$, is equal to the flux of heat conducted through the clothing, $\dot{Q}_{p}$, and that dissipated from the outer surface of the clothing by convection, $\dot{\mathrm{Q}}_{\mathrm{c}}$, and radiation, $\dot{\mathrm{Q}}_{\mathrm{r}}$. Figure 3 shows the overall thermal balance of the human body. As seen from Fig. 3 the flux

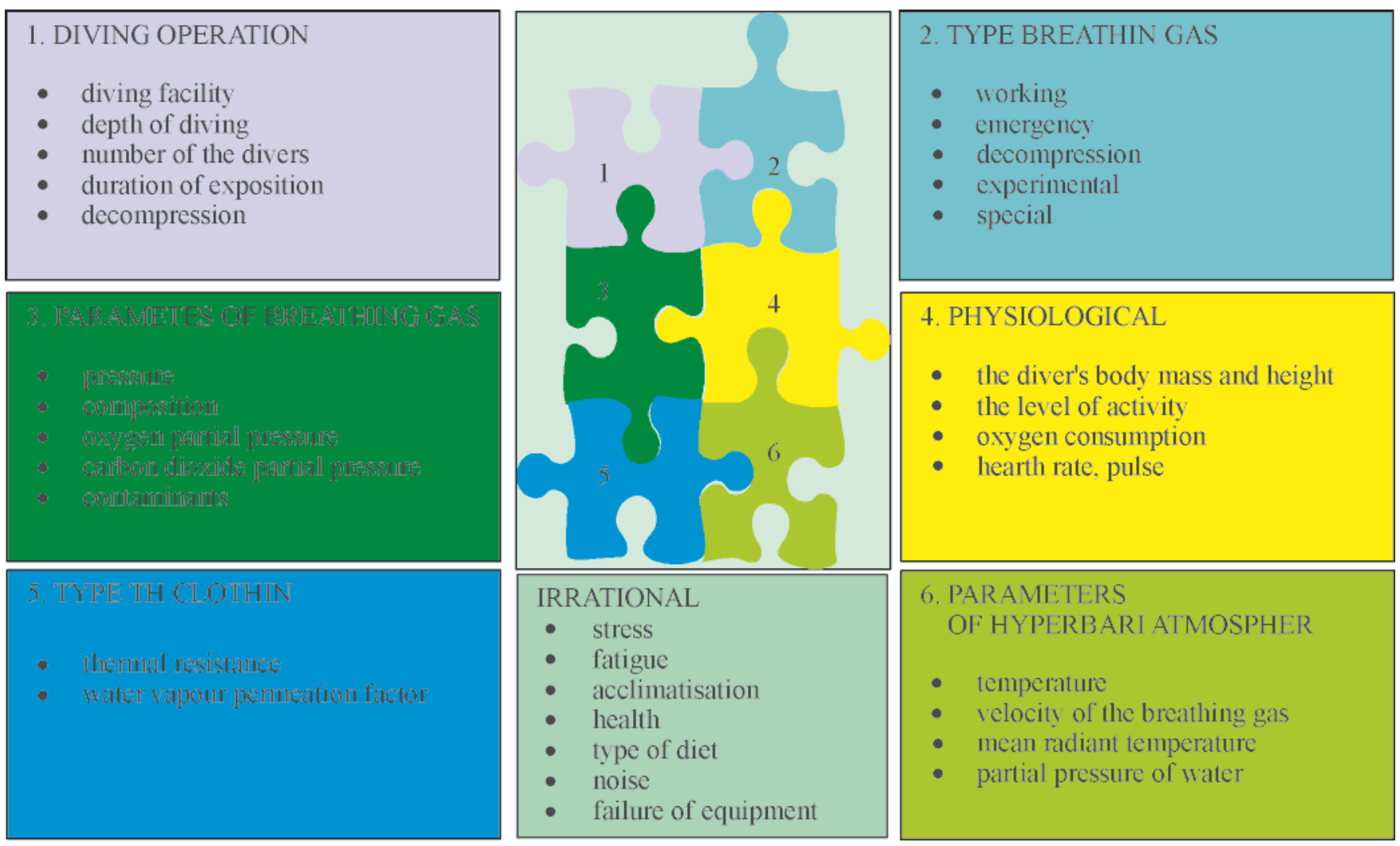

Fig. 3. Factors which influence thermal comfort in the hyperbaric facility. 


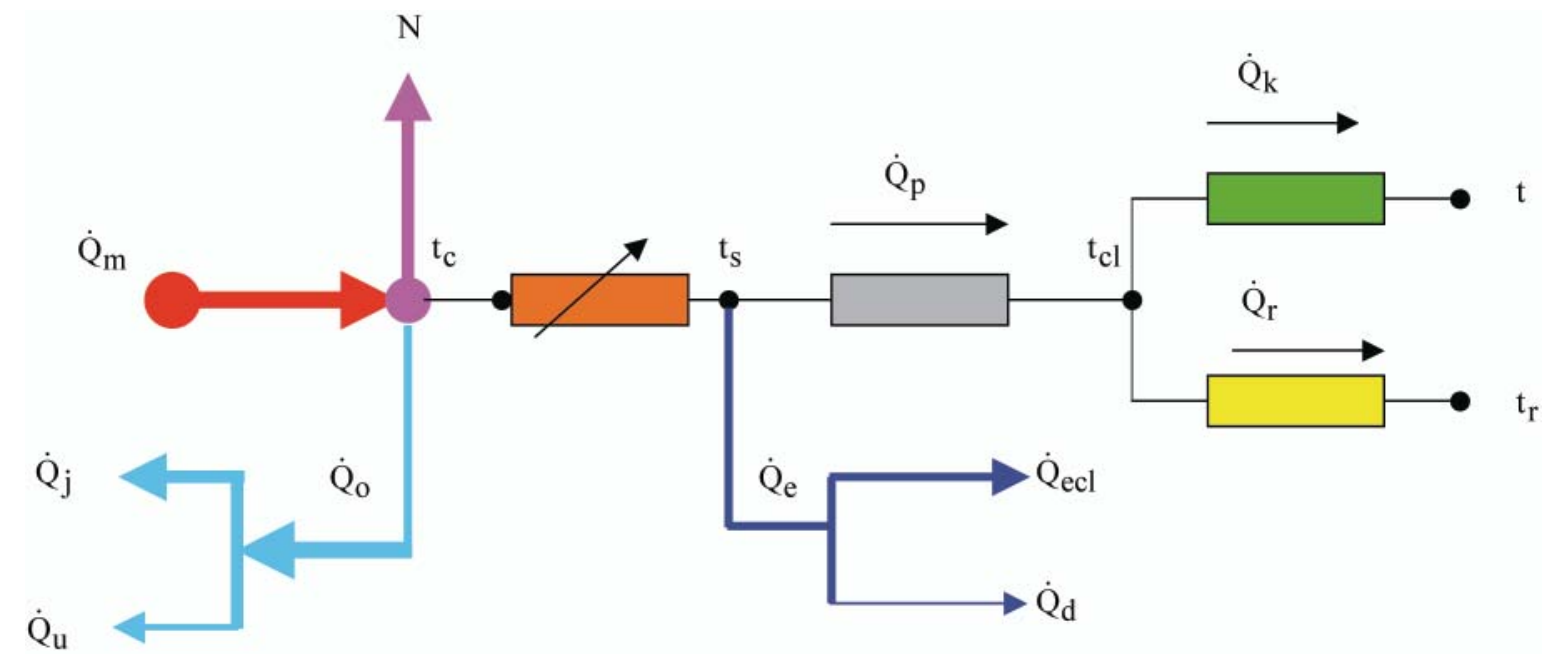

Fig. 4. Overall thermal balance of the human body

of heat loss by respiration, $\dot{\mathrm{Q}}_{0}$, and by evaporation from the skin, $\dot{\mathrm{Q}}_{\mathrm{e}}$, are not driven by the temperature difference directly.

The flux of metabolic heat released in oxidation processes in human body is partly converted into the external power $\mathrm{N}$ and the internal body heat flux $\dot{\mathrm{Q}}$, hence thermo-regulatory system maintains the core temperature $\mathrm{t}_{\mathrm{c}}$ approximately constant:

$$
\dot{\mathrm{Q}}_{\mathrm{m}}=\dot{\mathrm{q}}_{\mathrm{m}} \cdot \mathrm{A}_{\mathrm{Du}}=\dot{\mathrm{Q}}+\mathrm{N}
$$

External mechanical efficiency is defined as [2]:

$$
\eta_{\mathrm{d}}=\frac{\mathrm{N}}{\dot{\mathrm{Q}}_{\mathrm{m}}}
$$

By introducing the equation (4) to equation (3) the following is obtained:

$$
\dot{\mathrm{Q}}=\dot{\mathrm{Q}}_{\mathrm{m}}\left(1-\eta_{\mathrm{d}}\right)
$$

The flux of heat loss by respiration consists of the flux of dry respiration heat loss, $\dot{\mathrm{Q}}_{\mathrm{o}}$, and the latent respiration heat loss $\dot{\mathrm{Q}}_{\mathrm{ou}}$ :

$$
\dot{\mathrm{Q}}_{\mathrm{o}}=\dot{\mathrm{Q}}_{\mathrm{oj}}+\dot{\mathrm{Q}}_{\mathrm{ou}}
$$

The flux of heat loss by evaporation consists of flux of heat loss by water vapour diffusion through skin and sweat evaporation from the skin:

$$
\dot{\mathrm{Q}}_{\mathrm{e}}=\dot{\mathrm{Q}}_{\mathrm{d}}+\dot{\mathrm{Q}}_{\mathrm{ecl}}
$$

The heat loss by sweat evaporation is affected by skin temperature and the activity level.The skin assists in thermal homeostasis. The blood vessels and sweat glands located in the skin are activated due to thermal environmental conditions. Vasodilatation which allows increased blood to flow through the artery, sweat secretion and evaporation are the most important ways by which man attempts to lose excess of body heat. In cold conditions sweat is not secreted, muscles under the surface of the skin contract lifting the hair follicle upright and cause "goose bumps". Vasoconstriction enables to direct blood away from the skin and towards the warmer core of the body. This prevents blood against losing heat to the surroundings and also prevents the core temperature against decreasing.

The transfer of heat from skin to the outer surface of clothed body is rather complex as it consists of internal convection and radiation in material pores and conduction through material of the clothing itself, [2]. Flux of heat transferred from the skin to the outer surface of clothed body depends upon the total heat resistance to transfer from skin to the outer surface, skin temperature and temperature of the outer surface of the clothing:

$$
\dot{\mathrm{Q}}_{\mathrm{p}}=\frac{\left(\mathrm{t}_{\mathrm{s}}-\mathrm{t}_{\mathrm{cl}}\right) \cdot \mathrm{A}_{\mathrm{Du}}}{\mathrm{R}_{\mathrm{cl}}}
$$

The total heat resistance to transfer from skin to the outer surface of the clothed body is given as follows [2]:

$$
I_{\text {cla }}=\frac{0.155}{R_{c l}}
$$

The flux of heat dissipated by convection from the outer surface of the clothing, $\dot{Q}_{c}$, and radiation, $\dot{Q}_{r}$, depend upon ambient temperature and mean radiant temperature, emissivity of skin and clothing surface and thermal properties of the environment. Satisfaction of the heat balance equation (2) is the first sufficient condition for the diver's thermal comfort under long exposure to the hyperbaric environment. At a given activity level the skin temperature and the heat loss by evaporation are deemed the only physiological variables which influence the heat balance equation (2). Sensation of thermal comfort has been related to magnitude of the two variables:

$$
\begin{aligned}
& \mathrm{t}_{\mathrm{s}}=\mathrm{f}_{1}\left(\dot{\mathrm{q}}_{\mathrm{m}}\right), \quad \mathrm{a}<\mathrm{t}_{\mathrm{s}}<\mathrm{b} \\
& \dot{\mathrm{q}}_{\mathrm{e}}=\mathrm{f}_{2}\left(\dot{\mathrm{q}}_{\mathrm{m}}\right), \quad \mathrm{c}<\dot{\mathrm{q}}_{\mathrm{e}}<\mathrm{d}
\end{aligned}
$$

Man is in thermal comfort when the mean skin temperature and sweat secretion is maintained within the narrow limits $(a, b)$ and $(c, d)$, respectively, determined by the physiologists. According to the mathematical comfort model, [2], the equations (10) and (11) represent the second and third basic conditions for thermal comfort. The skin temperature for persons in thermal comfort, experimentally investigated in atmospheric air, can be expressed [2] as follows:

$$
\mathrm{t}_{\mathrm{s}}=35.7-0.026 \cdot \dot{\mathrm{q}}_{\mathrm{m}} \cdot\left(1-\eta_{\mathrm{d}}\right)
$$

Under the assumption that the skin temperature in hyperbaric environment is nearly the same [3] as in atmospheric air it is more convenient to express the second comfort condition (10) in function of the oxygen consumption, external mechanical efficiency and type of diet:

$$
\mathrm{t}_{\mathrm{s}}=35.7-0.032 \cdot \mathrm{C} \cdot \dot{\mathrm{V}}_{\mathrm{O}_{2}} \cdot\left(1-\eta_{\mathrm{d}}\right)
$$

Average value of the coefficient $\mathrm{C}$ which describes the utilization of $1 \mathrm{~cm}^{3}$ volume of oxygen can vary from $\mathrm{C}=18.85$ to $20.95 \mathrm{~J} / \mathrm{cm}^{3}$ depending on the proportion of carbohydrate, protein and fat being oxidized in the diver's organism [3]. The second basic comfort condition [2] enables to determine heat loss by evaporation of sweat secretion. It can be expressed for the hyperbaric environment as follows: 


$$
\dot{\mathrm{q}}_{\mathrm{e}}=\frac{\dot{\mathrm{Q}}_{\mathrm{e}}}{\mathrm{A}_{\mathrm{Du}}}=\mathrm{w} \cdot \beta \cdot \mathrm{r} \cdot \mathrm{F}_{\mathrm{pcl}} \cdot\left(\mathrm{p}_{\mathrm{s}}-\varphi \cdot \mathrm{p}_{\mathrm{sg}}\right)
$$

Area of the nude body surface, i.e. DuBois area, is expressed by the following equation [2]:

$$
\mathrm{A}_{\mathrm{Du}}=0.203 \cdot \mathrm{m}^{0.425} \cdot \mathrm{h}^{0.725}
$$

Skin wetness is defined [1] as follows:

$$
\mathrm{W}=\frac{\dot{\mathrm{Q}}_{\mathrm{e}}}{\dot{\mathrm{Q}}_{\mathrm{e} \max }}=0.02+0.4\left[1-\exp \left(-0.01034 \cdot \dot{\mathrm{q}}_{\mathrm{m}}+0.6\right)\right](16)
$$

The clothing moisture permeation factor $\mathrm{F}_{\mathrm{pcl}}$ describes the „,cooling efficiency" of sweating on the surface for a clothed human body [10]. The permeation efficiency factor $\mathrm{F}_{\mathrm{pcl}}$ has been derived theoretically for the different kinds of the hyperbaric breathing mixtures [8]:

$F_{p c l}=\frac{I_{d m}}{I_{d m}+I_{d c l}}=\left(1+\frac{0.155 \cdot R_{w} \cdot T_{s} \cdot \lambda_{a} \cdot I_{c l a} \cdot \beta}{D_{w-m}}\right)^{-1}$

By substituting all the terms of heat loss derived in [8], and thermal comfort basic conditions into the heat balance equation (2) the following is obtained:

$$
\begin{gathered}
\dot{\mathrm{q}}_{\mathrm{m}}\left(1-\eta_{\mathrm{d}}\right)-\frac{0.127 \cdot \beta \cdot \mathrm{r} \cdot\left(\mathrm{p}_{\mathrm{s}}-\varphi \cdot \mathrm{p}_{\mathrm{sg}}\right)}{4.58+3.46 \cdot \mathrm{v}}+ \\
-0.8895 \cdot 10^{-11} \cdot \dot{\mathrm{q}}_{\mathrm{m}} \cdot \mathrm{r} \cdot\left(\mathrm{p}_{\mathrm{s}}-\varphi \cdot \mathrm{p}_{\mathrm{sg}}\right)+ \\
-4.1 \cdot 10^{-9} \cdot \dot{\mathrm{q}}_{\mathrm{m}} \cdot \mathrm{c}_{\mathrm{p}} \cdot \mathrm{p} \cdot \mathrm{R}^{-1} \cdot\left(\mathrm{t}_{\mathrm{ex}}-\mathrm{t}\right)+ \\
-\mathrm{w} \cdot \beta \cdot \mathrm{r} \cdot \mathrm{F}_{\mathrm{pcl}} \cdot\left(\mathrm{p}_{\mathrm{s}}-\varphi \cdot \mathrm{p}_{\mathrm{sg}}\right)= \\
=\frac{\lambda \cdot\left(\mathrm{t}_{\mathrm{s}}-\mathrm{t}_{\mathrm{cl}}\right)}{4.03 \cdot 10^{-3} \cdot \mathrm{I}_{\mathrm{cla}}}=\alpha \cdot \mathrm{f}_{\mathrm{cl}} \cdot\left(\mathrm{t}_{\mathrm{cl}}-\mathrm{t}\right)+ \\
\quad+4 \cdot 10^{-8} \cdot \mathrm{f}_{\mathrm{cl}} \cdot\left(\mathrm{T}_{\mathrm{cl}}^{4}-\mathrm{T}_{\mathrm{r}}^{4}\right)
\end{gathered}
$$

The comfort equation derived for the hyperbaric environment can be expressed in function of breathing mixture pressure, composition and thermal properties (specific heat, thermal conductivity, viscosity and density), diver's activity, thermal resistance of the clothing, gas temperature, mean radiant temperature, relative humidity and velocity of the breathing mixture, (18).

The comfort equation (18) makes it possible to calculate all combinations of the above specified variables which are responsible for thermal comfort in the hyperbaric chamber. Moreover, it is possible to determine the comfort temperature inside the hyperbaric facility and all terms of the heat dissipated from the human body exposed to the hyperbaric environment. It's worth to accentuate that thermal comfort is felt very individually.

\section{THE RESULTS}

The comfort equation was solved under the following assumptions:

- the depth of simulated diving: $g=90,190,290,390,490$, $590 \mathrm{~m}$;

- the breathing gas: oxygen + helium, (HELIOX), oxygen +hydrogen (HYDROX);

- the relative humidity of the breathing gas: $\varphi=0.4,0.5,0.6$, $0.7,0.8,0.9,1$ at each depth;

- the relative velocity of the breathing gas: $\mathrm{v}=0.1,0.15,0.2$, $0.25,0.3 \mathrm{~m} / \mathrm{s}$;
- the mean radiant temperature: $\mathrm{t}=0,10,20,30,40,50{ }^{\circ} \mathrm{C}$;

- the Du Bois area: $\mathrm{A}_{\mathrm{Du}}=1.8 \mathrm{~m}^{2}$;

- the diver was clothed in a clothing of the total heat transfer resistance from skin to the outer surface of $\mathrm{I}_{1}=0.2 \div 1.1$ clo, clothing area factor $\mathrm{f}_{\mathrm{cl}}=0,8,1$ clo $=0.155 \mathrm{~m}^{2} \mathrm{~K} / \mathrm{W}$;

- the activity levels: the sedendary activity $\dot{\mathrm{q}}_{\mathrm{m}}=58 \mathrm{~W} / \mathrm{m}^{2}$, medium work activity $\dot{\mathrm{q}}_{\mathrm{m}}=90 \mathrm{~W} / \mathrm{m}^{2}$, intensive work activity $\dot{\mathrm{q}}_{\mathrm{m}}=120 \mathrm{~W} / \mathrm{m}^{2}$.

The comfort equation has been solved for relevant combinations of the above specified variables and the results have been presented in the form of the diagrams. The curves in Fig. 5 and Fig. 6 (gas pressure versus comfort temperature with gas velocity as a parameter) represent the comfort lines i.e. lines drawn through points which satisfy the equation (17) and thus provide the thermal comfort in HELIOX and HYDROX breathing mixtures under the following assumptions: the relative humidity of breathing gas $\varphi=0.7$, sedendary activity level $\dot{\mathrm{q}}_{\mathrm{m}}=58 \mathrm{~W} / \mathrm{m}^{2}$, clothing thermal resistance $\mathrm{I}_{\text {cla }}=0.37$ clo, mean radiant temperature $\mathrm{I}_{\text {cla }}=0.37$.

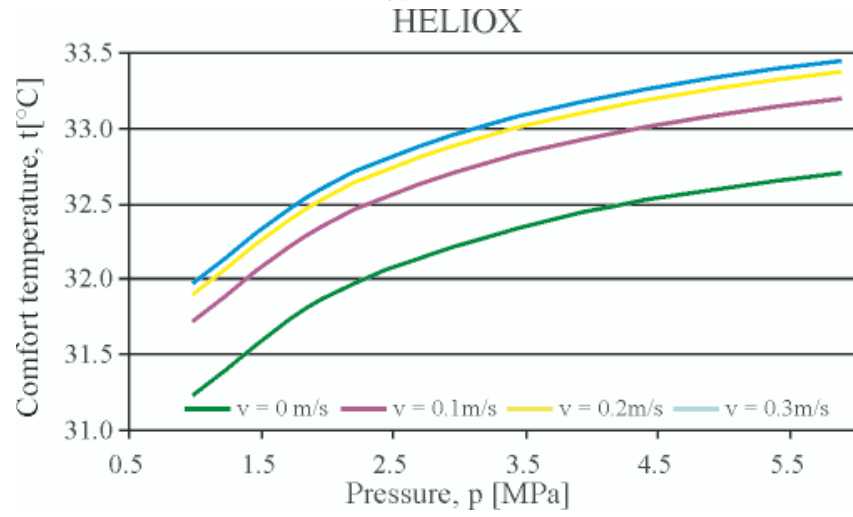

Fig. 5. Comfort lines for HELIOX (pressure versus comfort temperature with parameter of relative gas velocity) under the following assumptions: $\dot{q}_{m}$ $=58 \mathrm{~W} / \mathrm{m}^{2}, I_{c l a}=0.37 \mathrm{clo}, \varphi=0.4, t=30^{\circ} \mathrm{C}$

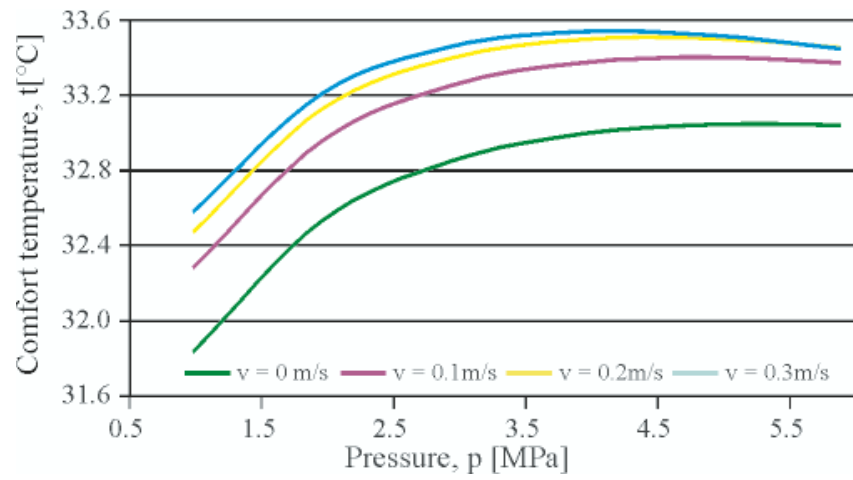

Fig. 6. Comfort lines for HYDROX (pressure versus comfort temperature with relative gas velocity as a parameter) under the following assumptions: $\dot{q}_{m}=58 \mathrm{~W} / \mathrm{m}^{2}, I_{\text {cla }}=0.37 \mathrm{clo}, \varphi=0.4, t_{r}=30^{\circ} \mathrm{C}$

From Fig. 5 and Fig. 6 it is evident that the total pressure of the breathing gas exerts a large effect on thermal comfort. To compensate body heat losses and achieve thermal comfort within the gas pressure range of $\mathrm{p}=0.98 \div 5.88 \mathrm{MPa}$ and gas relative velocity range of $\mathrm{v}=0 \div 0.3 \mathrm{~m} / \mathrm{s}$ it is necessary to increase the comfort temperature by $\Delta \mathrm{t} \cong 2.2 \mathrm{~K}$. As it follows from calculations despite pressure range, at $\mathrm{p}=$ const the increase of relative gas velocity from $\mathrm{v}=0$ to $\mathrm{v}=0.3 \mathrm{~m} / \mathrm{s}$ should be compensated for by the comfort temperature increase of $\Delta \mathrm{t} \cong 0.7 \mathrm{~K}$.

Fig. 7 and Fig. 8 show comfort lines which illustrate the relationship between comfort temperature in HELIOX and HYDROX atmospheres, mean radiant temperature and relative 
gas velocity under the following assumptions: $\dot{\mathrm{q}}_{\mathrm{m}}=58 \mathrm{~W} / \mathrm{m}^{2}$, $\mathrm{I}_{\text {cla }}=0.37$ clo, $\varphi=0.7, \mathrm{t}_{\mathrm{r}}=30^{\circ} \mathrm{C}, \mathrm{p}=0.98 \mathrm{MPa}$. As it follows from Fig. 7 and Fig. 8 at constant relative gas velocity increase of mean radiant temperature should be compensated by comfort temperature decrease. As seen from Fig. 7 and Fig. 8, the comfort lines cross each other at the mean radiant temperature $\mathrm{t}_{\mathrm{r}}=20^{\circ} \mathrm{C}$ and comfort temperature $\mathrm{t}=34.1^{\circ} \mathrm{C}$ for HELIOX, and $\mathrm{t}_{\mathrm{r}}=20^{\circ} \mathrm{C}$ and $\mathrm{t}=34^{\circ} \mathrm{C}$ for HYDROX, respectively.

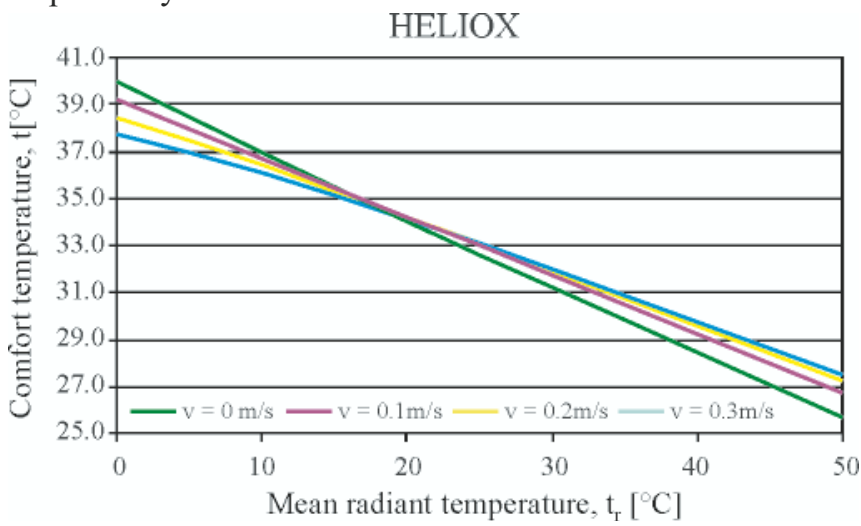

Fig. 7. Comfort lines for HELIOX (mean radiant temperature versus comfort temperature with relative gas velocity as a parameter) under the following assumptions: $\dot{q}_{m}=58 \mathrm{~W} / \mathrm{m}^{2}, I_{\text {cla }}=0.37 \mathrm{clo}, \varphi=0.7, p=0.98 \mathrm{MPa}$ HYDROX

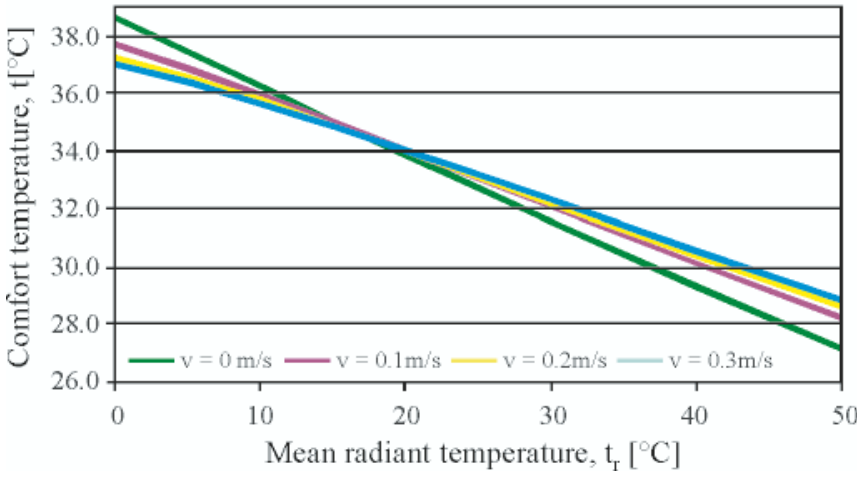

Fig. 8. Comfort lines for HYDROX (mean radiant temperature versus comfort temperature with gas velocity as parameter) at the following assumptions: $\dot{q}_{m}=58 \mathrm{~W} / \mathrm{m}^{2}, I_{c l a}=0.37 \mathrm{clo}, \varphi=0.7, p=0.98 \mathrm{MPa}$

The comfort lines cross each other where the temperature of the breathing mixture is equal to the mean temperature of the clothed body since the convective heat transfer here will be zero, independent of the relative velocity. To the right of the crossing point the temperature of the outer surface of the clothing is higher than the breathing mixture temperature and an increase in the relative velocity will therefore require an increase of the breathing mixture temperature or changing mean radiant temperature in order to maintain thermal comfort. To the left of the crossing point the temperature of the outer surface of the clothing is lower than the breathing mixture temperature and an increase in gas velocity will therefore require a decrease in the mixture temperature or changing mean radiant temperature to maintain thermal comfort.

Fig. 9 and Fig. 10 show comfort lines for HELIOX and HYDROX, which illustrate the relationship between comfort temperature, pressure and the total heat transfer resistance of clothing under the following assumptions: $\dot{\mathrm{q}}_{\mathrm{m}}=58 \mathrm{~W} / \mathrm{m}^{2}$, $\varphi=0.4, \mathrm{t}_{\mathrm{r}}=25^{\circ} \mathrm{C}, \mathrm{v}=0 \mathrm{~m} / \mathrm{s}$.

From Fig. 9 and Fig. 10 it is evident that for all types of the total heat transfer resistance of clothing increase of gas pressure should be compensated for by increase of comfort temperature. As it follows from Fig. 9 and Fig. 10 at $\mathrm{I}_{\text {cla }}=$ const, increase of pressure from $p=0.98 \mathrm{MPa}$ to $\mathrm{p}=5.88 \mathrm{MPa}$ should be compensated for by increase of comfort temperature by $\Delta \mathrm{t}=0.7 \mathrm{~K}$ for HELIOX and by $\Delta \mathrm{t}=0.6 \mathrm{~K}$ for HYDROX. To maintain thermal comfort in HELIOX atmosphere of pressure $\mathrm{p}=2.94 \mathrm{MPa}$ and in HYDROX atmosphere of pressure $\mathrm{p}=1.96 \mathrm{MPa}$ increase of the total heat transfer resistance of clothing from $\mathrm{I}_{\text {cla }}=0.3$ clo (light clothing ensemble) to $\mathrm{I}_{\text {cla }}=1.1$ clo (heavy working ensemble) should be compensated for by decrease of comfort temperature of $\Delta t=1.3 \mathrm{~K}$ for HELIOX and of $\Delta t=0.8 \mathrm{~K}$ for HYDROX.

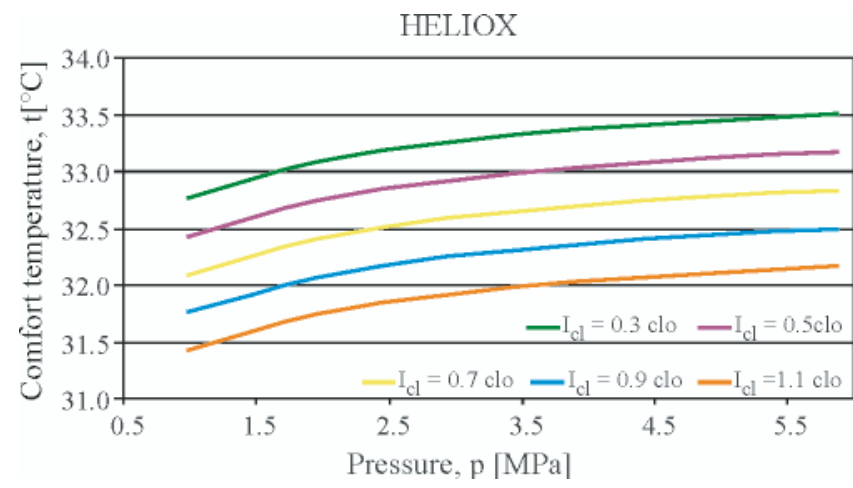

Fig. 9. Comfort lines for HELIOX (pressure versus comfort temperature with the total heat transfer resistance of clothing as a parameter) under the following assumptions: $\dot{q}_{m}=58 \mathrm{~W} / \mathrm{m}^{2}, \varphi=0.4, t_{r}=25{ }^{\circ} \mathrm{C}, v=0 \mathrm{~m} / \mathrm{s}$

HYDROX

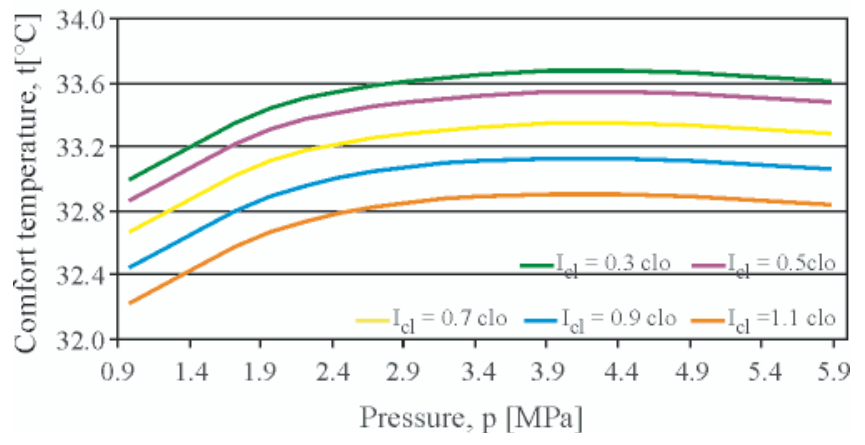

Fig. 10. Comfort lines for HYDROX (pressure versus comfort temperature with the total heat transfer resistance of clothing as a parameter) under the following assumptions: $\dot{q}_{m}=58 \mathrm{~W} / \mathrm{m}^{2}, \varphi=0.4, t_{r}=25^{\circ} \mathrm{C}, v=0 \mathrm{~m} / \mathrm{s}$

Fig. 11 and Fig. 12 show the relationship between comfort temperature, pressure and the diver's activity in HELIOX and HYDROX atmosphere under the following assumptions: $\varphi=$ $0.6, \mathrm{t}_{\mathrm{r}}=30^{\circ} \mathrm{C}, \mathrm{v}=0 \mathrm{~m} / \mathrm{s}, \mathrm{I}_{\text {cla }}=0.2$ clo. It is evident from Fig. 11 and Fig. 12 that at the constant activity of the diver, comfort temperature increases due to increase of pressure. To maintain thermal comfort at $\mathrm{p}=$ const and increasing activity of the diver it is necessary to reduce comfort temperature.

HELIOX

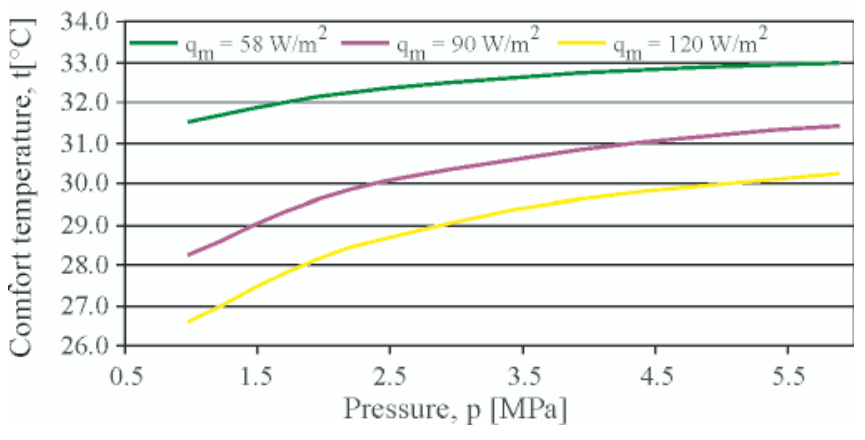

Fig. 11. Comfort lines for HELIOX (pressure versus comfort temperature with the diver activity as a parameter) under the following assumptions: $I_{\text {cla }}=0.2 \mathrm{clo}, \varphi=0.6, t_{r}=30^{\circ} \mathrm{C}, v=0 \mathrm{~m} / \mathrm{s}$ 
HYDROX

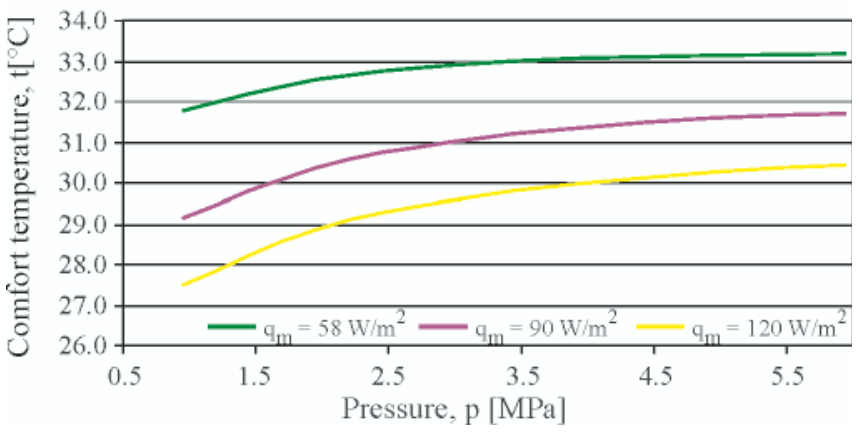

Fig. 12. Comfort lines for HYDROX (pressure versus comfort temperature with the diver activity as a parameter) under the following assumptions: $I_{\text {cla }}=0.2$ clo, $\varphi=0.6, t_{r}=30^{\circ} \mathrm{C}, v=0 \mathrm{~m} / \mathrm{s}$

As it follows from Fig. 11 and Fig. 12 to maintain thermal comfort at the pressure $\mathrm{p}=0.981 \mathrm{MPa}$, change in the diver's activity from $\dot{\mathrm{q}}_{\mathrm{m}}=58 \mathrm{~W} / \mathrm{m}^{2}$ (sedendary) to $\dot{\mathrm{q}}_{\mathrm{m}}=120 \mathrm{~W} / \mathrm{m}^{2}$ (intensive work) should be compensated for by the comfort temperature decrease $\Delta \mathrm{t}=4.9 \mathrm{~K}$ in the case of HELIOX, and $\Delta \mathrm{t}=3.0 \mathrm{~K}$ in the case of HYDROX. At the diver's sedendary activity $\dot{\mathrm{q}}_{\mathrm{m}}=58 \mathrm{~W} / \mathrm{m}^{2}$ the pressure increase from $\mathrm{p}=0.98 \mathrm{MPa}$ to $\mathrm{p}=5.88 \mathrm{MPa}$ should be compensated for by the comfort temperature increase $\Delta \mathrm{t}=1.5 \mathrm{~K}$ both for HELIOX and HYDROX.

Fig. 13 and Fig. 14 show comfort lines for HELIOX and HYDROX under the following assumptions: $\mathrm{I}_{\text {cla }}=0.37 \mathrm{clo}$, $\varphi=0.6, \mathrm{t}_{\mathrm{r}}=30^{\circ} \mathrm{C}, \mathrm{p}=1.96 \mathrm{MPa}$. As it follows from Fig. 13 and Fig. 14 at constant activity an increase of relative gas velocity should be compensated for by an increase of comfort temperature. At v = const an increase of diver's activity should be compensated for by a decrease of comfort temperature.

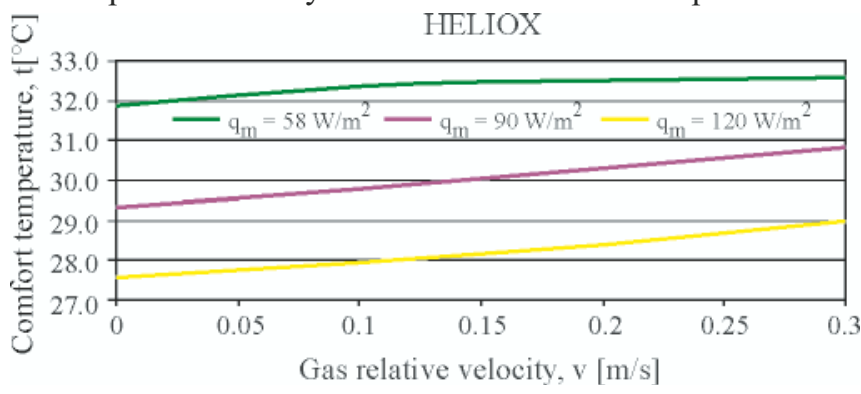

Fig. 13. Comfort lines for HELIOX (gas velocity versus comfort temperature with the diver activity as a parameter) under the following assumptions: $I_{\text {cla }}=0.37$ clo, $\varphi=0.6, t_{r}=30^{\circ} \mathrm{C}, p=1.96 \mathrm{MPa}$

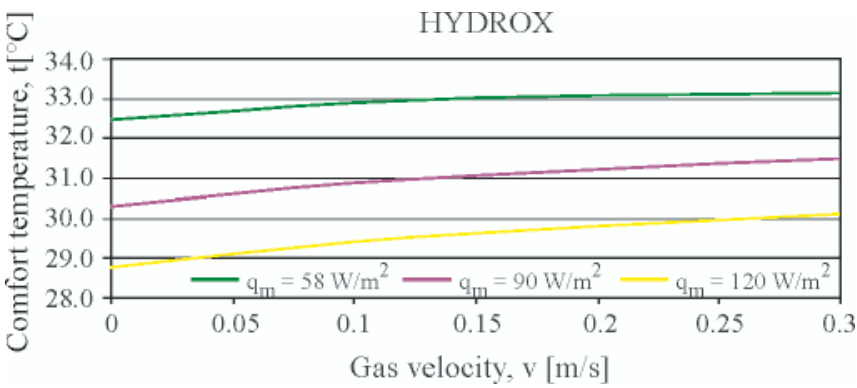

Fig. 14. Comfort lines for HYDROX (relative gas velocity versus comfort temperature with the diver activity as a parameter) under the following assumptions: $I_{\text {cla }}=0.37$ clo, $\varphi=0.6, t_{r}=30^{\circ} \mathrm{C}, p=1.96 \mathrm{MPa}$

As seen from Fig.13 and Fig. 14, to maintain the sedendary $\operatorname{diver}\left(\dot{\mathrm{q}}_{\mathrm{m}}=58 \mathrm{~W} / \mathrm{m}^{2}\right)$ and working diver $\left(\mathrm{q}_{\mathrm{m}}=120 \mathrm{~W} / \mathrm{m}^{2}\right)$ in thermal comfort, when relative gas velocity changes from $\mathrm{v}=0$ to $\mathrm{v}=0.3 \mathrm{~m} / \mathrm{s}$, it is necessary to increase comfort temperature by $\Delta \mathrm{t}=0.7 \mathrm{~K}$ for HELIOX and $\Delta \mathrm{t}=3.5 \mathrm{~K}$ for HYDROX. As shown in Fig. 13 and Fig. 14 the change in the diver's activity from $\dot{\mathrm{q}}_{\mathrm{m}}=58 \mathrm{~W} / \mathrm{m}^{2}$ to $\dot{\mathrm{q}}_{\mathrm{m}}=120 \mathrm{~W} / \mathrm{m}^{2}$, at constant relative gas velocity of $\mathrm{v}=0.1 \mathrm{~m} / \mathrm{s}$, should be compensated for by the temperature decrease $\Delta \mathrm{t}=4.4 \mathrm{~K}$ for HELIOX and $\Delta \mathrm{t}=3.5 \mathrm{~K}$ for HYDROX.

Fig. 15 shows the relationship between comfort temperature, pressure and relative humidity of HYDROX under the following assumptions: $\dot{\mathrm{q}}_{\mathrm{m}}=58 \mathrm{~W} / \mathrm{m}^{2}, \mathrm{I}_{\text {cla }}=0.37 \mathrm{clo}, \mathrm{v}=0 \mathrm{~m} / \mathrm{s}$, mean radiant temperature $\mathrm{t}_{\mathrm{r}}=25^{\circ} \mathrm{C}$.

As it follows from Fig. 15 at constant gas relative humidity an increase in pressure will increase comfort temperature. At the pressure $\mathrm{p}=0.98 \mathrm{MPa}$ a change in HYDROX relative humidity from $\varphi=0.4$ to $\varphi=1$ should be compensated for by the comfort temperature decrease $\Delta \mathrm{t}=0.6 \mathrm{~K}$.

At higher pressure of breathing mixture comfort lines are convergent and asymptotically approach the comfort temperature $\mathrm{t}=33.6^{\circ} \mathrm{C}$. It means that there is no significant influence of breathing mixture relative humidity on comfort temperature. As it follows from the obtained results the influence of the breathing gas relative humidity on the magnitude of comfort temperature is not significant however very important for sweat evaporation and comfort sensation. Poor evaporative rate may result in a diver's feeling of high humidity (discomfort) and will prevent from evaporative cooling of the skin.

HYDROX

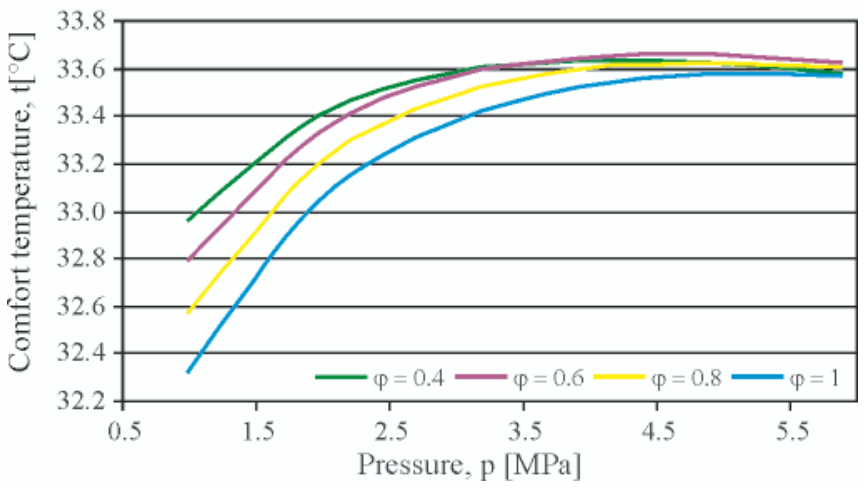

Fig. 15. Comfort lines for Hydrox (gas pressure versus comfort temperature with the relative humidity as a parameter) under the following assumptions: $\dot{q}_{m}=58 \mathrm{~W} / \mathrm{m}^{2}, I_{\text {cla }}=0.37 \mathrm{clo}, v=0 \mathrm{~m} / \mathrm{s}, t_{r}=25^{\circ} \mathrm{C}, p=0.98 \mathrm{MPa}$.

By using the comfort equation it is possible, for any type of the breathing mixture (composition, pressure), type of clothing and type of the diver's activity, to calculate all reasonable combinations of the temperature, relative humidity and velocity of the breathing gas and mean radiant temperature. The water vapour transport coefficient in the hyperbaric environment can be computed from the experimental relationship for vapour transport coefficient in helium-oxygen mixture $[4,5]$ or theoretically [8]. The results of the experiments demonstrated a great influence of the total pressure on the water vapour transport coefficient in the helium rich atmosphere. To make an assessment of the thermal comfort equation derived for the hyperbaric facility, its theoretical and an experimental verification is recommended. Fig. 16 shows comparison between the theoretical results obtained from the thermal comfort equation and the experimental results published in $[12,16,18]$.

The theoretical solution of the thermal comfort equation, shown in Fig.16, was obtained under the following assumptions: $\dot{\mathrm{q}}_{\mathrm{m}}=58 \mathrm{~W} / \mathrm{m}^{2}, \mathrm{I}_{\text {cla }}=0.37 \mathrm{clo}, \mathrm{v}=0 \mathrm{~m} / \mathrm{s}, \varphi=0.4, \mathrm{t}_{\mathrm{r}}=30^{\circ} \mathrm{C}$. As it follows from Fig. 16 the theoretical results are in compliance with those previously published in [16] for HELIOX, and are higher approximately by $\Delta \mathrm{t}=2 \mathrm{~K}$ than the temperature predicted in $[12,13,19]$. Comparison of the results is difficult. 


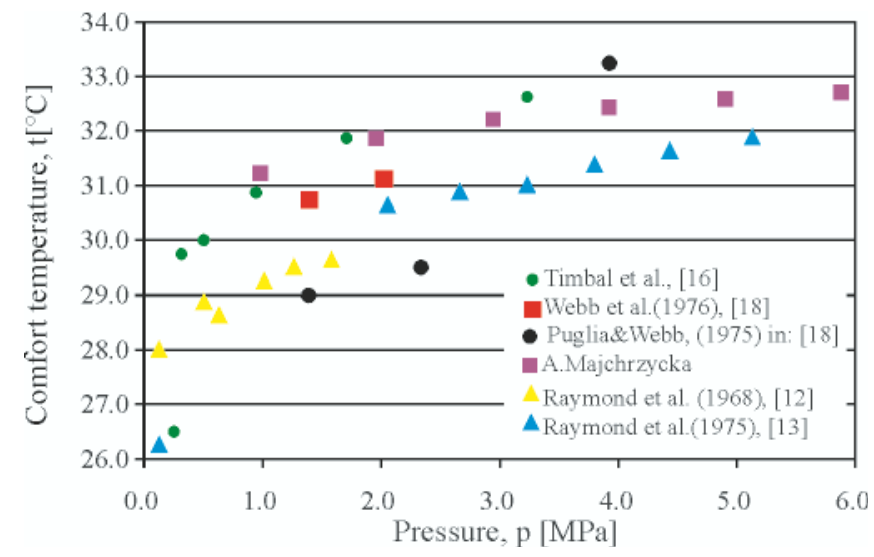

Fig. 16. Comparison between the theoretical results obtained from the thermal comfort equation and the experimental results published in $[12,16,18]$

After experimental verification, the mathematical model of thermal comfort can serve as a very useful mathematical tool in designing the environmental life support systems of the hyperbaric facilities. The derived thermal comfort equation enables to simulate different thermal conditions in the hyperbaric facility with taking into account the most important variables which influence thermal comfort.

\section{CONCLUSIONS}

- On the basis of the mathematical model of human body thermal exchange and two basic thermal comfort conditions, the comfort equation for hyperbaric environment was derived

- The comfort equation enables to calculate all those combinations of environmental variables which would create thermal comfort in the hyperbaric facility,

- By using the comfort equation it is possible, for any type of the breathing mixture (composition, pressure), type of clothing and the diver's activity, to calculate all reasonable combinations of the gas temperature, relative humidity and velocity and mean radiant temperature,

- The comfort equation was solved for the hyperbaric breathing mixtures: HELIOX and HYDROX in the assumed range of the parameters in diving up to the depth of $\mathrm{g}=590 \mathrm{~m}$,

- As follows from the solution of the comfort equation, the required comfort temperature in the hyperbaric facilities increases progressively along with increasing pressure of HELIOX and HYDROX breathing mixtures, and the comfort temperatures are similar in values for both atmospheres,

The results obtained under the assumptions: $\dot{\mathrm{q}}_{\mathrm{m}}=58 \mathrm{~W} / \mathrm{m}^{2}$, $\mathrm{I}_{\text {cla }}=0.37 \mathrm{clo}, \mathrm{v}=0 \mathrm{~m} / \mathrm{s}, \varphi=0.4, \mathrm{t}_{\mathrm{r}}=30^{\circ} \mathrm{C}$ for the pressure range of $\mathrm{p}=0.98 \div 5.88 \mathrm{MPa}$, have shown the comfort temperature range of $\mathrm{t}=31.6 \div 33.6{ }^{\circ} \mathrm{C}$ to be nearly the same for HELIOX and HYDROX.

- The theoretical results found for HELIOX are comparable with those previously experimentally determined and reported in $[12,13,16,18]$. There are no available data concerning the relationship between comfort temperature and pressure in $\mathrm{H}_{2}-\mathrm{O}_{2}$ mixture.

- The presented paper has concluded the first stage of the research aimed at mathematical modelling of thermal comfort in hyperbaric facility, and the second stage should be aimed at experimental verification of the derived model,

- After experimental verification, the mathematical model of thermal comfort can serve as a very useful mathematical tool in designing and operating the environmental life support systems of hyperbaric facilities, as it enables to simulate different thermal conditions in the hyperbaric facility.

\section{NOMENCLATURE}

$\mathrm{A}_{\mathrm{Du}}-\mathrm{Du}$ Bois area, human body surface area, $\left[\mathrm{m}^{2}\right]$,

$c_{p}-$ specific heat of the breathing mixture, $[\mathrm{J} / \mathrm{kg} \mathrm{K}]$,

$\mathrm{D}_{\mathrm{w}-\mathrm{m}}$ - diffusion coefficient of water vapour into breathing mixture, $\left[\mathrm{m}^{2} / \mathrm{s}\right]$,

$\mathrm{f}_{\mathrm{cl}} \quad-$ ratio of the surface area of the clothed body and the surface area of the nude body,

$\mathrm{F}_{\mathrm{pcl}}-$ moisture permeation factor,

$\mathrm{I}_{\mathrm{cla}}^{\mathrm{pcl}}-$ thermal resistance to heat transfer from skin to outer surface of the clothed body, [clo],

$\mathrm{I}_{\mathrm{dcl}} \quad-$ diffusive resistance for water vapour through the clothing, $\left[\mathrm{m}^{2} \mathrm{sPa} / \mathrm{kg}\right]$,

$I_{d m} \quad-$ diffusive resistance for water vapour through the breathing mixture, $\left[\mathrm{m}^{2} \mathrm{sPa} / \mathrm{kg}\right]$,

$\mathrm{N} \quad-$ external power, $[\mathrm{N}]$,

$\mathrm{p} \quad-$ total pressure of the breathing mixture, [Pa],

$\mathrm{p}_{\mathrm{s}}, \mathrm{p}_{\mathrm{sg}}-$ saturated water vapour pressure at skin (surface) temperature and ambient breathing gas temperature, $[\mathrm{Pa}]$, respectively

$\dot{\mathrm{q}}_{\mathrm{m}} \quad$ - diver's activity level, metabolic rate, $\left[\mathrm{W} / \mathrm{m}^{2}\right]$,

$\dot{\mathrm{Q}} \quad$ - flux of internal heat produced by the body, [W],

$\hat{Q}_{d} \quad-$ flux of heat loss resulting from water vapour diffusion through the skin, [W],

$\dot{\mathrm{Q}}_{\mathrm{e}} \quad-$ flux of evaporative heat loss, [W],

$\dot{\mathrm{Q}}_{\mathrm{ecl}}$ - flux of heat loss resulting from sweat evaporation from the skin, [W],

$\dot{\mathrm{Q}}_{\mathrm{e} \max }-$ flux of evaporative heat loss at skin wetness $\mathrm{w}=1$,

$\dot{\mathrm{Q}}_{\mathrm{m}}$ - flux of metabolic heat released in oxidation processes, [W],

$\dot{\mathrm{Q}}_{0} \quad$ - flux of respiration heat loss, [W],

$\mathrm{Q}_{\mathrm{oj}}^{\mathrm{o}} \quad$ - flux of dry respiration heat loss, [W]

$\dot{\mathrm{Q}}_{\mathrm{ou}}^{\mathrm{j}}$ - flux of latent respiration heat loss, [W]

$\dot{\mathrm{Q}}_{\mathrm{k}} \quad$ - flux of convective heat dissipated from the outer surface of the clothed body, [W],

$\dot{\mathrm{Q}}_{\mathrm{o}} \quad$ - flux of heat loss from the skin to the outer surface of the clothed body, [W],

$\dot{\mathrm{Q}}_{\mathrm{r}} \quad$ - flux of heat loss resulting from radiation from the outer surface of the clothed body, [W],

$\mathrm{r} \quad-$ specific latent heat of vaporisation, $[\mathrm{J} / \mathrm{kg}]$,

$\mathrm{R}, \mathrm{R}_{\mathrm{w}}$ - gas constant of the breathing mixture, water, $[\mathrm{J} / \mathrm{kg} \mathrm{K}]$,

$\mathrm{t} \quad{ }^{\mathrm{w}}$ - comfort temperature, $\left[{ }^{\circ} \mathrm{C}\right.$,

$\mathrm{t}_{\mathrm{cl}}, \mathrm{T}_{\mathrm{cl}}-$ temperature of the outer surface of the clothing, $\left[{ }^{\circ} \mathrm{C}, \mathrm{K}\right]$,

$\mathrm{t}_{\mathrm{ex}}{ }^{\mathrm{cl}}$ - temperature of expired gas, $\left[{ }^{\circ} \mathrm{C}\right]$

${ }^{\mathrm{ex}} \mathrm{T}_{\mathrm{r}}-$ mean radiant temperature, $\left[{ }^{\circ} \mathrm{C}, \mathrm{K}\right]$,

$\mathrm{t}_{\mathrm{s},}^{\mathrm{r},} \mathrm{T}_{\mathrm{s}}^{\mathrm{r}}-$ temperature of the skin surface, $\left[{ }^{\circ} \mathrm{C}, \mathrm{K}\right]$,

$\mathrm{s}$, - skin wetness,

$\mathrm{V}-\quad$ - relative velocity of the breathing mixture, $[\mathrm{m} / \mathrm{s}]$,

$\dot{\mathrm{V}}_{\mathrm{O} 2}$ - oxygen consumption, [ $\left.\mathrm{cm}^{3} / \mathrm{min}\right]$,

$\mathrm{x}_{\mathrm{i} 2}-$ molar fraction of breathing gas component,

$\alpha-$ convective heat transfer coefficient, $\left[\mathrm{W} / \mathrm{m}^{2} \mathrm{~K}\right]$

$\beta-$ water vapour transport coefficient in the hyperbaric environment, $\left[\mathrm{kg} / \mathrm{m}^{2} \mathrm{sPa}\right]$,

$\varphi \quad-$ relative humidity of the breathing mixture,

$\lambda, \lambda_{\mathrm{a}}-$ thermal conductivity of the breathing mixture and atmospheric air, [W/mK], respectively,

$\eta \quad-$ viscosity of the breathing mixture, $[\mathrm{kg} / \mathrm{ms}]$

$\eta_{d} \quad-$ mechanical efficiency of diver.

\section{BIBLIOGRAPHY}

1. Azer N.Z, S.Hsu: The use of modelling human response in the analysis of thermal comfort of indoor environments. Proceedings of a Symposium Held at the National Bureau of Standards Gaithersburg, Maryland, February 1977.

2. Fanger P.O.: Thermal comfort. Danish Technical Press, Copenhagen, 1970. 
3. lynn E. T., Vorosmarti J. Jr, Modell H. I.: Research Report 2173, Navy Experimental Diving Unit, Washington, 1974

4. Gardette B., Gortan C.,Delauze H.G.: Helium in-hydrogen out. A new diving technique. Proceedings of the $23^{\text {rd }}$ Annual Scientific Meeting of the European Underwater and Baromedical Society, Bled (Slovenia), 1997.

5. Hamilton R.W. Jr.: Breathing mixtures. Technical Memorandum CRL-T-750, Ocean Systems and Development Laboratory, Tarrytown, New York, December 1973.

6. Kozak T, Majchrzycka A.: The influence of pressure, temperature and kind of gas on the coefficient of water evaporation from the free surface. Boiling and Condensation International Proceedings, Riga, 1998.

7. Kozak T., Majchrzycka A.: The influence of pressure and temperature on rate of water evaporation from the free surface. Advances in Engineering Heat Transfer. Proc.of Second Baltic Heat Transfer Conference, Ed. B.Sunden, E. Blums, A. Żukauskas, Computational Mechanics Publications, Southampton, Boston, 1995.

8. Majchrzycka A: The comfort temperature in the hyperbaric environment (in Polish). Doctoral thesis, Technical University of Szczecin, Szczecin, 1982.

9. Moor T. O., Morlock J. F., Lally D. A., Hong S. K.: Thermal cost of saturation diving: respiratory and whole body heat loss at 16.1 ATA. Proc. of the Third Symposium on Underwater Physiology, Freeport, Bahamas, 1972.

10.Nishi Y., Gagge A.P.: Moisture Permeation of Clothing - A Factor governing Thermal Equilibrium and Comfort. ASHRAE Transactions, vol.76,1,1970.

11. Raymond L.: Temperature problems in multiday exposures to high pressures in the sea. Thermal balance in hyperbaric atmospheres. Proc. of the Third Symposium on Underwater Physiology, Baltimore, 1966.

12.Raymond L.W., Bell W.H. 2nd, Bondi K.R., Lindberg C.R.: Body temperature and metabolism in hyperbaric helium atmospheres. J. Appl. Physiol.,1968, May 24(5).

13. Raymond LW, Thalmann E, Lindgren G, Langworthy HC, Spaur WH, Crothers J, Braithwaite,W, Berghage T.:
Thermal homeostasis of resting man in helium-oxygen at 1-50 atmospheres absolute, in: Undersea Biomed. Res., 1975, March 2(1).

14.Taylor L.: Diving with gas mixes other than air. Mixed gas diving, ed. Watersport, http://www-personal.umich.edu/ lpt/ mixhistory.htm,

15.Shilling C. W., Werts M. F., Schandelmeier N. R., Ed.: The underwater handbook: A guide to physiology and performance for the engineer. Plenum Press, New York, 1976.

16.Timbal J., Varène P., Vieillefond H., Guenard H., L'Huiller J.: Metabolism and heat losses of resting man in hyperbaric helium atmosphere. Journal of Applied Physiology, 36, 4, 1974.

17.Varene P., Timbal J., Viellefond H., Guenard H., L'Huiller J.: Energy balance of man in simulated dive from 1.5 to 31 ATA. Proc. of the Third Symposium on Underwater Physiology, Freeport, Bahamas, 1972.

18.Webb P., Troutman S.J.Jr., Fratalli V., Dwyer J., Moore T.O.,Morlock J.F,Smith R.M., Ohta Y.: Energy balance in saturation diving. Report ADA041834 Naval Medicine Research and Development Command, Bethesdea, Maryland, 1976.

19. Webb P.: Body heat loss in undersea gaseous environments. Aerospace Medicine, 10, 1970.

20.Webb P.: The thermal drain of comfortable hyperbaric environments. Naval Research Review, 3, 1973.

\section{CONTACT WITH THE AUTHOR}

Anna Majchrzycka, Ph. D.

Faculty of Mechanical Engineering and Mechatronics, Department of Heat Engineering,

West Pomeranian University of Technology

Al. Piastów 19

71-310 Szczecin, POLAND

e-mail: anna.majchrzycka@zut.edu.pl 